\title{
A theoretical model and empirical results linking website interactivity and usability satisfaction
}

\author{
Paul Benjamin Lowry, Trent Spaulding, Taylor Wells, \\ Greg Moody, Kevin Moffit, Sebastian Madariaga \\ Information Systems Department \\ Marriott School \\ Brigham Young University \\ Paul.Lowry@BYU.edu
}

\begin{abstract}
Usability is a key component of websites that are commercially successful. Interactivity has been inconclusively linked to website usability. This study strengthens the theoretical understanding of how interactivity affects usability by measuring user satisfaction-a subconstruct of usability-across bookstore and e-card websites. We build on theoretical models from Liu and Shrum [17] and Khalifa and Liu [15]. Users were asked to perform tasks of varying levels of interactivity at bookstore and e-card websites. Measures were obtained for the user's expectations of, desires for, and satisfaction with the websites. Results indicate that interactivity is successfully able to increase website satisfaction. Finally, implications for practitioners, limitations of the study, and directions for future research are addressed.
\end{abstract}

\section{Introduction}

The tremendous growth in e-commerce and the strong link between usability and trust have spawned a significant volume of research on improving website usability. Website usability has been defined and studied in terms of a variety of aspects: learnability, memorability, errors/safety, satisfaction [19]; improving online sales [4]; satisfaction with the appearance of an interface [20]; website organization [23]; reliability [11]; and navigation [11].

Though not yet conclusive, interactivity is a promising design factor that has been indirectly linked to website usability [23]. Interactivity has been defined as reciprocal communication between at least two entities, with website interactivity generally involving communication between a human user and the website [17]. Recently, researchers studying interactivity have developed several interactivity frameworks that have been validated in experimental situations, e.g. [6, 17]. Yet, research on website interactivity is still in its early stages, and a theoretical gap exists in explaining and predicting the link between interactivity and usability.

Although it may seem intuitive that websites with a high degree of interactivity are more usable than less-interactive websites, there is little theoretical and empirical evidence to support this claim. In fact, this assumption may be incorrect. So far, research shows that interactivity can be useful, value-neutral, or detrimental to a website, depending on the circumstances [16]. Thus, understanding how interactivity affects usability is essential to the progress of research on usability in e-commerce websites.

While usability literature provides guidelines for improving website usability, many of these guidelines are not validated by empirical or theoretical evidence, rendering them incorrect, useless, or inapplicable in some contexts [9]. Consequently, practitioners often blindly follow unproven guidelines [7]. Many usability guidelines largely ignore interactivity aspects of user engagement, and also comment that closely following existing usability guidelines "does not necessarily mean that the site will attract viewers, stimulate their interests and curiosity, or leave them with a positive impression" [7] p. 218. Thus, simply following practitioner-based usability guidelines will not necessarily provide appropriate levels of website interactivity.

With the increasing demand for e-commerce, it is becoming increasingly important to augment current usability literature with research based on validated theory and empirical data. In response to the existing gaps in interactivity literature, we raise several research questions: Is there a link between interactivity and website usability? If there is, what are the theoretical explanations for this link? What are 
the key subconstructs of interactivity that have an effect on perceived website usability? In practical terms, what website features induce positive perceptions of interactivity?

In addressing these research questions, we attempt to theoretically and empirically examine the link between interactivity and website usability. Because usability is a highly complex construct, we have limited the scope of our theory to focus on usability perceptions that relate to user satisfaction with a website. Other usability subconstructs such as learnability, memorability, efficiency, error prevention, etc., will likely have different theoretical connections to interactivity and will require additional investigation in further studies.

\section{Background literature}

\subsection{Interactivity}

Although many researchers have advanced varying definitions of interactivity, most of these definitions have a common thread. The interactivity construct usually refers to two-way communication and interchange in which two or more parties send related messages to each other [17]. Pavlik [24] defines interactivity as a "process of reciprocal influence" (p. 135). Rafaeli [25] specifies that interactive communication must involve messages in which subsequent messages are contingent on previous messages; in other words, any later message must refer to earlier messages. Stromer-Galley [30] reaffirms this requirement by defining interactivity as communication with a high degree of responsiveness and reflexivity, where "participants share the burden of communication equally, subverting hierarchical, linear structures of communication" p. 117. Similarly, Alba, Lynch, Weitz, and Haniszewski [1] propose that the two main dimensions of interactivity are response time and contingency.

Research on interactivity generally focuses on face-to-face $(\mathrm{FtF})$ interpersonal communication [6]. However, Ha and James [12] contend that the definition of interactivity based on interpersonal communication is too restrictive to suit technical communication. This assertion is especially relevant when considering work that occurs over the World Wide Web and related technologies. In the realm of technology, the concept of interactivity includes both humans and computers as parties in an interaction.

\subsection{Website Interactivity}

We consider website interactivity to be a subset of interactivity that is focused solely on the interaction between websites and users. In this sense, website interactivity can be broadly defined as any action a user or a website takes while a user is visiting a website. In many cases, these actions are intended to achieve a predetermined end-user goal with the website, such as accessing information-whether users are seeking specific information or just browsing [30]. Other goals may include business transactions or even entertainment [30].

Two-way communication, active control, and synchronicity form the basis of a powerful, yet simple, definition of website interactivity provided by Liu and Shrum [17] and further developed in [16]. Two-way communication refers to bi-directional flow of communication between the communicators. Active control is present when a user is given the ability to choose information and guide the interaction. Synchronicity indicates the timing of information exchange; a more concurrent or simultaneous exchange between two entities is a more synchronous interaction than an exchange with a longer lapse between responses. These three subconstructs of interactivity form the basis for studying the relationship between website interactivity and website usability.

\subsection{Website Usability}

More usable websites tend to create more positive attitudes toward online stores and increase revisit rates, whereas websites with low usability have the opposite effect [4]. Nielsen [19] defines usability in terms of learnability, efficiency, memorability, user errors, and satisfaction. Although the elements in both definitions are given in reference to usability in general, they are also presumed to apply specifically to website usability.

The attribute of usability that we measure in this study is subjective satisfaction. Subjective satisfaction refers to how pleasant a user finds it to use a computer application or a website [19]. Subjective satisfaction measures have been judged competent indicators of the satisfaction subconstruct of website usability [27]. In our research, we chose to use a modified measure of satisfaction as developed in [18].

\section{Theoretical Model}

To build a theoretical model that explains and predicts the link between interactivity and usability subconstruct of satisfaction, we extend Khalifa and Liu's [15] theory of e-commerce disconfirmation, 
which was built on disconfirmation theory [21]. Accordingly, satisfaction is a state of mind that is an interaction among three basic componentsexpectations, desires, and perceived performance. We discuss these three components in the section below, explaining how the components interrelate with confirmation and disconfirmation, and how confirmation and disconfirmation relate to satisfaction.

Expectations are beliefs or subjective predictions about a product's attributes or performance at some time in the future, or the likelihood that a product is associated with certain attributes, benefits, and outcomes, which are oriented toward the future and are relatively changeable [5]. Individuals form these beliefs (subjective predictions) under a state of imperfect information about the true attributes of a product. The creation of these beliefs is generally based on social norms.

Desires are the levels of attributes and benefits that consumers believe will enable them to achieve their desired outcome. Evaluations of the extent to which these attributes, benefits, or outcomes lead to the attainment of a person's desired outcomes are relatively stable [29]. Desires are based upon a person's values and are mainly internal and separate from expectations that are mainly related to how an individual thinks a product will perform.

Perceived performance is characterized by a user's perception of how a product is able to fulfill a user's expectations upon actual usage [18]. Perceived performance is the user's perception of the product based upon its fulfillment of expectations. Whether this perceived performance leads to increased or decreased satisfaction will depend upon the confirmation or disconfirmation of the expectations and desire of the individual user. After an individual experiences a product, the individual will perform a mental assessment, comparing their desires and expectations against the perceived performance of the product. Confirmation or disconfirmation is the result of that assessment. Confirmation occurs when the expectations of the individual match the perceived performance of the product. Disconfirmation occurs when there is a mismatch between expectations and perceived performance. The individual's desires will determine whether the confirmation or disconfirmation is either positive or negative. If the outcome is confirmed, yet it was not a desirable event by the user, it will be a negative event and lead to a decrease in satisfaction. However, if the user desires this outcome, the event will be a positive event and lead to an increase in satisfaction.

Having applied the theory of disconfirmation to the realm of website satisfaction, we now extend e- commerce disconfirmation theory to further explain the point of confluence between website satisfaction and website interactivity. When computers are used to facilitate transactions, humans expect computers to follow rules of social interaction and that when this social interaction does not occur it actually decreases satisfaction with the website [22]. This concurs with the assertion that "human communication processes and outcomes vary systematically with the degree of interactivity that is afforded and/or experienced" [6] p. 34. This interaction or interactivity is defined as "The degree to which a communication exchange resembles human discourse" [13] p. 223. Humans, therefore, expect certain levels of interactivity in communication-even if communication involves a website.

The effects of fulfilled and unfulfilled expectations and desires of interactivity in websites are preliminarily supported by website interactivity research. $\mathrm{Wu}$ [32] showed a strong, positive correlation between positive perceptions toward a website and interactivity. Similar positive, non-causal relationships have been found in other studies $[8,33]$.

Liu and Shrum [17] provide a literature review and theoretical proposition to support the notion that increased control, two-way communication, and synchronicity improve interactivity and communication with websites. In particularly, Liu and Shrum create untested theoretical propositions that (1) link increased active control to increased learning, self-efficacy, and satisfaction; (2) link two-way communication to learning and satisfaction; and (3) link synchronicity to satisfaction. The commonality between all three-which we test here-is increased satisfaction. Part of Liu and Shrum's theory rests on the assertion that interactive websites cause users to be more actively engaged than in one-way communication.

Preliminary research supports many aspects of Liu and Shrum's [17] theory-showing how interactivity can be increased by increasing the three subconstructs of interactivity: active control, two-way communication, and synchronicity. Research involving experiments on active control, in the context of simulated home shopping, shows that increased levels of control can improve memory and learning, as long as the task is not difficult [3]. Applied psychological research on control shows that increased control is linked to increased satisfaction whereas decreased control is linked to dissatisfaction [14] and increased stress [2]. Little research has been conducted showing the tie between two-way communication and website interactivity, though there is a preliminary tie between increased two-way communication and satisfaction [10]. Finally, delays 
in synchronicity, operationalized through Internet download times, cause unfavorable attitudes toward documents, while quicker download times caused favorable attitudes [26]. Similarly, delay in websites causes unfavorable attitudes toward websites [10].

Given this background support, and the untested propositions by Liu and Shrum [17], we extend ecommerce disconfirmation theory to propose that as a website's levels of active control, two-way communication, and synchronicity approach the levels expected by consumers in a FtF setting, those consumers will be more satisfied than they would be with levels of interactivity below what is expected and desired by consumers. Our extension of ecommerce disconfirmation theory is depicted in Figure 1.

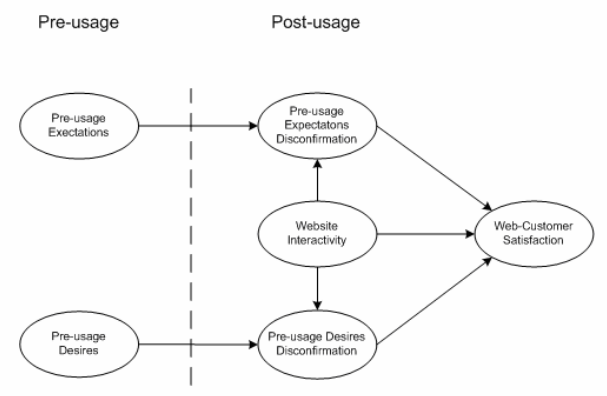

Figure 1. Theory of e-commerce disconfirmation extended to website satisfaction and interactivity

We now operationalize hypotheses to test various elements of our theoretical extension of e-commerce disconfirmation theory to interactivity. If Liu's [16] three measures of interactivity (control, two-way communication, and synchronicity) hold as subconstructs of interactivity then they should be highly related:

H1: The perceived measures of active control, twoway communication, and synchronicity should be highly correlated with each other.

If the theory of e-commerce disconfirmation extends to the case of interactivity in websites, then website users' preexisting expectations and desires for websites should have no direct bearing on their perceived satisfaction of websites:

H2: The measure of expectations should have no linear relationship with satisfaction.

H3: The measure of desires should have no linear relationship with satisfaction.
If the theory of disconfirmation extends for the case of interactivity in websites, then disconfirmation should be the main determinant of website satisfaction. Positive disconfirmation occurs when there is a positive difference between the actual interactivity of a website and the expectations and desires a user has for a website. For example, if a website is highly interactive but a user has moderate expectations, then the difference should be positive. Satisfaction should be a positive function of positive disconfirmation:

H4: The measure of expectations disconfirmation should have a positive linear relationship with satisfaction.

H5: The measure of desires disconfirmation should have a positive linear relationship with satisfaction.

If $\mathrm{H} 4$ and $\mathrm{H} 5$ are true, then it naturally follows that as a website becomes more interactive, it becomes less likely that negative disconfirmation will occur. As a result, the more interactive a website is, the more likely a user is to experience satisfaction:

H6: The measure of interactivity (through active control, two-way communication, and synchronicity) should have a positive linear relationship with satisfaction

\section{Methodology}

We tested the interactivity and satisfaction of a group of e-card websites and a group of collegebookstore websites. E-card and bookstore websites were chosen for three reasons. (1) There are many websites in both domains that are easy to locate and that include a wide range of variety. (2) Websites from both domains require interaction with the website to complete the intended task. (3) The subjects in this study could easily be considered perspective consumers of products or services in both domains. In the case of college-bookstores, university students are the main consumers. The experimental design featured satisfaction as the dependent variable and interactivity as the independent variable.

\subsection{Participants}

The participants were 120 students from an introductory information systems course at a large, private university. Participants were sophomore-level business students from a variety of business majors; $20 \%$ of the participants were female and $80 \%$ were male. Participants were given extra credit and $\$ 10$ as incentives for contributing. Human-participants approval was granted for this study, and all major protocols were followed, such as informed consent. 
Those who desired similar extra credit but did not want to participate in this study were given alternative assignments. No member of the research team was involved in teaching the course. Each participant was sent an email with instructions on how to complete the experiment. Each participant was randomly assigned two treatments - one from the bookstore domain, and one from the e-card domain.

\subsection{Measures}

Interactivity. The actual interactivity of the websites was a perceived measure created by three external judges. This allowed us to have an independent measure of interactivity that could be compared to the participants' expectations and desires to evaluate their disconfirmation of expectations and desires. To develop this measure, we analyzed dozens of websites for college bookstores and e-card sites in a preliminary attempt to find sites of low, medium, and high interactivity. Of these, 18 websites were selected that appeared to offer a wide range of interactivity. These websites were then independently rated by three expert judges according to Liu's [16] proven measures of interactivity. Of the 18 websites, 9 were taken from the bookstore domain and the other 9 were taken from the e-card domain. After independent evaluations were conducted, the three judges then met and agreed

Table 2. Selected websites

\begin{tabular}{|l|l|}
\hline Type of website & Title of site \\
\hline Bookstore & AVC Bookstore \\
\hline Bookstore & USU Bookstore \\
\hline Bookstore & USC Bookstore \\
\hline Bookstore & Linfield Bookstore \\
\hline Bookstore & Cornell Bookstore \\
\hline Bookstore & Univ. of Arizona Bookstore \\
\hline Bookstore & Harvard Bookstore \\
\hline Bookstore & Casper College Bookstore \\
\hline Bookstore & Ohio Valley Bookstore \\
\hline E-card & Webshots \\
\hline E-card & Disney e-cards \\
\hline E-card & Crossdaily \\
\hline E-card & Partymerchant.com \\
\hline E-card & Takingitglobal.org \\
\hline E-card & Hallmark \\
\hline E-card & Specially4y.net \\
\hline E-card & Regards.com \\
\hline E-card & E-cards.com \\
\hline
\end{tabular}

on an interactivity score for each website (see Table 2 for list of websites). These websites were then randomly assigned to participants.

Desires and expectations. The perceived measures for desires and expectations were modified from a usability instrument in McKinney et al. [18]. The only difference between the original instrument and our version is that the former included measures on reliability and information quality which we chose to exclude because they apply more to usability than to interactivity. Our instrument retained all of the McKinney items that pertain to dimensions of interactivity (active control, two-way communication, and synchronicity). The same instrument is used to measure both expectations and desires, with the sole exception that every instance of the word "expect" or "desire" was substituted accordingly.

Participants were asked what they expected or desired from a bookstore website or from an e-card website. Each question was rated on 1 to 7 Likert-like scale. Both the expectation measure (14 items, $\alpha=$ 0.97 ) and the desire measure (14 items, $\alpha=0.96$ ) were highly reliable.

Disconfirmation. To measure expectations disconfirmation, we simply measured the difference between a website's judged interactivity rating (the likely experienced website interactivity) and a user's expectations. Desires disconfirmation is measured in the same manner. Positive disconfirmation occurs when there is a positive difference between the two measures. For example, if a website is highly interactive, but a user has only moderate expectations, then the difference is positive.

Satisfaction. We chose to use a modified measure of satisfaction as developed by McKinney et al. [18]). Again, the difference between our measure of satisfaction and the original items from [18] is that we eliminated items regarding reliability and information quality because they did not pertain to our study. Our measure, like the original measure, had high reliability (13 items, $\alpha=0.98$ ).

\subsection{Procedures and Controls}

Once participants were randomly assigned to their treatments (one e-card site and one bookstore site), they were sent an introductory e-mail that welcomed them to the study, included links to their treatments, and outlined strict rules and procedures (as detailed in Appendix 4). Participants were given 10 days to complete their work. The initial e-mail also included instructions to complete a pre-experiment survey according to our modified version of McKinney et al.'s [18] measure of satisfaction. After completing the pre-experiment survey, each participant was told to navigate to a specific e-card website and perform a specific e-card task. Once this was completed, participants were required to take a post-experiment survey in which they completed the satisfaction measure for their assigned e-card site. They then were directed to a specific college-bookstore website where 
they performed a specific bookstore task. They then completed the satisfaction measure for their assigned college-bookstore site. In both tasks, participants were instructed not to navigate away from their assigned websites before completing the task.

For the e-card task, participants were asked to find a "get well" card and send it to an e-mail address set up for the experiment. "Get well" cards are not seasonal, which means they will not be featured prominently during any specific time of the year, but are common enough to be available at each e-card site. The task in the college bookstore domain was to locate a specific title and then complete the ordering process (stopping just short of the point of actual purchase). Most of the participants completed the task by ordering 1984, by George Orwell. However, on two of the nine websites that book was not available, and other books were assigned. We chose 1984 and the alternate titles because they were not featured on the front page of any website; this limitation required the user to browse the bookstore sites by navigating according to the website design.

\section{Analysis}

To test $\mathrm{H} 1$ - the perceived measures of active control, two-way communication, and synchronicity should be highly correlated with each other-we used Pearson's correlations and factor analysis. These correlations were all highly statistically significant. Exploratory factor analysis showed all three measures loading onto one component, explaining $86.9 \%$ of the variance. These analyses provide support for $\mathrm{H} 1$.

To test $\mathrm{H} 2$ - the measure of expectations should have no linear relationship with satisfaction-we performed linear regression of expectations on satisfaction. The regression results were $\beta=0.04, t=$ $0.61_{1,237}$, and $\mathrm{p}=0.55$, which fully support $\mathrm{H} 2$.

To test H3 - the measure of desires should have no linear relationship with satisfaction-we performed linear regression of desires on satisfaction. The regression results were $\beta=$ $-0.07, \mathrm{t}=-1.14_{1,237}$, and $\mathrm{p}=0.26$, which fully support H3.

To test $\mathrm{H} 4$ - the measure of expectations disconfirmation should have a positive linear relationship with satisfaction-we performed linear regression of expectations disconfirmation on satisfaction. The regression results were $\beta=0.38, \mathrm{t}=$ $6.38_{1,237}$, and $\mathrm{p}=0.000$, which fully support $\mathrm{H} 4$.

To test $\mathrm{H} 5$ - the measure of desires disconfirmation should have a positive linear relationship with satisfaction-we performed linear regression of desires disconfirmation on satisfaction. The regression results were $\beta=0.41, t=6.88_{1,237}$, and $\mathrm{p}=0.000$, which fully support $\mathrm{H} 5$.
To test H6- the measure of interactivity through active control, two-way communication, and synchronicity should have a positive linear relationship with satisfaction-we performed linear regression of interactivity on satisfaction. The regression results were $\beta=0.49, \mathrm{t}=8.66_{1,237}$, and $\mathrm{p}=$ 0.000 , which fully support H6.

\section{Discussion}

This research extended e-commerce disconfirmation theory by testing the effects of interactivity upon user satisfaction with websites. We found that the perceived interactivity subconstructs of active control, two-way communication, and synchronicity were highly correlated with each other. We also provided support for extending the theory of e-commerce disconfirmation to websites because users' preexisting expectations and desires for websites had no direct bearing on their perceived satisfaction of websites. As predicted by the theory, the disconfirmation of desires and expectations experienced, based on the level of interactivity, directly affected satisfaction. Users who experienced higher levels of interactivity than they had expected and desired achieved much greater satisfaction than those who received less than their expectations and desires. By confirming several of the propositions given by Liu and Shrum [17], we further showed that the more interactive a website was, the more likely a user was to experience satisfaction.

\subsection{Contribution}

This study contributes to the theoretical understanding of how interactivity and interactive features affect satisfaction. Because user satisfaction has been identified as an important element in defining usability [19] and because poor website usability is a leading cause of distrust in e-commerce websites [28], increasing interactivity is a promising method of increasing consumer trust in e-commerce websites through improved usability. A greater understanding of the relationship between interactivity and usability provides several theoretical contributions by validating the theoretical models of Khalifa and Liu [15] and Liu and Shrum [17].

Another significant theoretical contribution is our extension of Khalifa and Liu's [15] theory of ecommerce disconfirmation to websites. We show that desires and expectations do not drive website usability satisfaction; instead (consistent with the theory of ecommerce disconfirmation), user satisfaction is driven by disconfirmation, which is based on perceived performance - in our case, website interactivity.

Our study also provides several contributions to practice. E-commerce website designers are 
constantly under pressure to provide a product that will deliver a competitive edge. Previously, no theoretical or empirical evidence existed that supported the role of interactivity in increasing website usability. This study begins to clarify the importance of having high levels of interactivity to increase usability and subsequent consumer trust.

Website designers should more seriously consider the three subconstructs of interactivity when creating website design. Specifically, our results suggest that the quality of the implementation of interactive features is more important than the existence of those features. Accordingly, website designers need to consider the quality of website features when designing a website. Increasing the interactivity of a website through quality interactive features will increase that site's usability.

\subsection{Limitations and Future Research}

A key limitation of this study is that although we showed that increased interactivity was beneficial in our sample websites, high interactivity is not necessarily always good. Our study used sites that had low to moderate levels of interactivity, generating results that show how interactivity has a positive impact upon user satisfaction. However, Sundar et al. [31] have suggested that there is a point where interactivity affects users negatively; Liu and Shrum [17] state that this point may be based upon the characteristics of the individual, and may occur when the interactivity level of the site is high. Future research needs to explore the effects of high levels of interactivity on website users.

Another limitation is that our study only focused on bookstore sites and e-card sites, with participants who were college students. Subsequent studies must be conducted to see how possible it is to generalize our findings to other contexts. Future research should consider other types of websites, such as auction sites, travel, blogs, etc., and should use research samples from populations other than university students. For example, two factors that can affect users' reactions to interactivity are (1) the user's desire for control and (2) the user's computer-mediated communication apprehension (CMCA) [17], both of which may possibly be influenced by a user's cultural background. In addition, other interactive tasks should also be explored; the task in our study involved browsing for information. Liu and Shrum [17] suggest that users browsing for information will be affected differently than users who are browsing for pleasure.

There may also be differences in decision-making tasks, etc. It would be helpful for practitioners to know how the purpose of a website affects the level of interactivity needed to increase user satisfaction, and which websites (if any) must limit their interactivity, or certain elements of interactivity to reach optimum levels of user satisfaction. For example, two-way communication while shopping for books may not be as important as two-way communication while participating in an online community. Further research making connections between the purpose of a website and the level of interactivity required for user satisfaction could prove invaluable.

Furthermore, because the subconstructs of active control, two-way communication, and synchronicity were so highly related to each other in our study, we cannot definitively determine the specific contribution each subconstruct makes to overall user satisfaction. It is extremely difficult to separate these three subconstructs using real-world websites, as all these features tend to appear together. Thus, experimental research could be conducted using artificial websites that only focus on selected arrangements of these subconstructs.

In this study we measured how confirmation or disconfirmation was affected by active control, twoway communication, and synchronicity. Disconfirmation is a measure of the difference between the pre-experimental measures (expectations and desires) and the judges' measure of interactivity (representing the perceived performance of the website). We showed that in our context, and consistent with our theory, user satisfaction is not driven by existing levels of expectations and desires; instead, it is driven by disconfirmation (positive or negative) of perceived performance. Yet disconfirmation and perceived performance are not necessarily the only constructs that influence satisfaction in a website context. Other drivers that may need to be incorporated into the theoretical model may include branding and aesthetics.

Another limitation of this study is that we used measures gathered by judges and by the participants in order to determine disconfirmation. Participants reported their desires, expectations and satisfaction. Judges determined the website interactivity scores, allowing us a consistent baseline to compare the actual levels of website interactivity. Future research should consider gathering data on website interactivity directly from the study participants. A measure gathered from the participants may not predict website interactivity as well as trained judges but could provide more participant-centered insights on disconfirmation.

Now that this study has developed the theoretical connection between interactivity and satisfaction, additional constructs need to be examined. Opportunities for future research include linking 
interactivity to more subconstructs of website usability, such as learnability, memorability, efficiency, and errors/safety. This would further our understanding of the role of interactivity in increasing website usability and potentially with consumer trust. Self-efficacy is another construct from Liu and Shrum's [17] model that needs to be considered in future empirical research.

\section{Conclusion}

Increasing consumer trust in websites is an implicit goal of this study. Since website usability has been linked to consumer trust [28], but there was a gap in the existing literature linking interactivity to website usability, we have attempted in this study to discover the link between interactivity and website usability. We found evidence that increased interactivity leads to increased satisfaction, an important component and indicator of usability.

This study confirms that improving interactivitywhich is what many practitioners are already doing to increase website transactions-does make a difference in increasing consumer trust in those transactions. In doing so, we provided a theoretical explanation and prediction of how website interactivity affects usability satisfaction through an extension of the theory of disconfirmation. This study builds a foundation for future research so that the roles of interactivity, and other usability subconstructs, can be fully understood, allowing ecommerce vendors to build online consumer trust and increase profitability. This foundation will continue to aid website designers in developing websites using interactivity features that are optimal for their domain.

\section{References}

[1] J. Alba, J. Lynch, B. Weitz, and C. Haniszewski, "Interactive home shopping: Consumer, retailer, and manufacturer incentives to participate in electronic marketplaces," Journal of Marketing, vol. 61, pp. 3853, 1997.

[2] J. H. Amirikhan, "Attributions as predictors of coping and distress," Personality and Social Psychology Bulletin, vol. 24, pp. 1006-1018, 1998.

[3] D. Ariely, "Controlling the information flow: Effects on consumers' decision-making and preferences," Journal of Consumer Research, vol. 27, pp. 233-248, 2000.

[4] S. A. Becker and F. E. Mottay, "A global perspective on web site usability," IEEE Software, vol. 18, pp. 54$61,2001$.

[5] A. Bhattacherjee, "Understanding information systems continuance: An expectation-confirmation model," MIS Quarterly, vol. 25, pp. 351-370, 2001.
[6] J. K. Burgoon, J. A. Bonito, B. Bengtsson, A. Ramirez Jr., A. E. Dunbar, and N. Miczo, "Testing the interactivity model: Communication processes, partner assessments, and the quality of collaborative work," Journal of Management Information Systems (JMIS), vol. 16, pp. 33-56, 2000.

[7] K. Chen and D. C. Yen, "Improving the quality of online presence through interactivity," Information \& Management, vol. 42, pp. 217-226, 2004.

[8] C.-H. Cho and J. D. Leckenby, "Interactivity as a measure of advertising effectiveness: Antecedents and consequences of interactivity in Web advertising," in Proceedings of the 1999 Conference of the American Academy of Advertising, M. S. Roberts, Ed. Gainesville, FL, USA: American Academy of Advertising, 1999, pp. 162-179.

[9] D. Cunliffe, "Developing usable web sites: A review and model," Internet Research, vol. 10, pp. 295-307, 2000 .

[10] B. G. C. Dellaert and B. Kahn, "How tolerable is delay? Consumers' evaluation of Internet web sites after waiting," Journal of Interactive Marketing, vol. 13, pp. 41-54, 1999.

[11] F. N. Egger, "From Interactions to Transactions: Designing the Trust Experience for Business-toConsumer Electronic Commerce." Eindhoven, Netherlands: Eindhoven University of Technology, 2003.

[12] L. Ha and E. L. James, "Interactivity reexamined: A baseline analysis of early business web sites," Journal of Broadcasting and Electronic Media, vol. 42, pp. 457-474, 1998.

[13] C. Heeter, "Implications of new interactive technologies for conceptualizing communication," in Media Use in the Information Age: Emerging Patterns of Adoption and Consumer Use, J. L. Salvaggio and J. Bryant, Eds. Hillsdale, NJ, USA: Lawrence Erlbaum Associates, 1989, pp. 221-225.

[14] T. A. Judge, J. E. Bono, and E. A. Locke, "Personality and job satisfaction: The mediating role of job characteristics," Journal of Applied Psychology, vol. 85, pp. 237-249, 2000.

[15] M. Khalifa and V. Liu, "The role of expectations and desires," International Journal of Electronic Commerce, vol. 7, pp. 31-49, 2003.

[16] Y. Liu, "Developing a scale to measure the interactivity of websites," Journal of Advertising Research, vol. 43, pp. 207-218, 2003.

[17] Y. Liu and L. J. Shrum, "What is interactivity and is it always such as good thing? Implications of definition, person, and situation for the influence of interactivity or advertising influence," Journal of Advertising, vol. 31, pp. 53-64, 2002.

[18] V. McKinney, Y. Kanghyun, and F. M. Zahedi, "The 
measurement of web-customer satisfaction: An expectation and disconfirmation approach,"

Information Systems Research (ISR), vol. 13, pp. 296 -

315,2002 .

[19] J. Nielsen, Usability Engineering. New York, NY, USA: Morgan Kaufmann, 1993.

[20] J. Nielsen, "Alertbox: Usability metrics," vol. 2004: Nielsen Norman Group, 2001.

[21] R. L. Oliver, "A cognitive model of the antecedents and consequences of satisfaction decisions," Journal of Marketing Research, vol. 17, pp. 460-469, 1980.

[22] A. Ovans, "Is your website socially savvy?" Harvard Business Review, vol. 77, pp. 20-21, 1999.

[23] J. W. Palmer, "Web site usability, design, and performance metrics," Information Systems Research (ISR), vol. 13, pp. 151-167, 2002.

[24] J. Pavlik, New Media Technology: Cultural and Commercial Perspectives. Boston, MA, USA: Allyn and Bacon, 1996.

[25] S. Rafaeli, "Interactivity: From new media to communication," in Advancing Communication Science: Merging Mass and Interpersonal Processes, R. Hawkins, J.Weimann, and S. Pingree, Eds. Newbury Park, CA, USA: Sage, 1988, pp. 110-134.

[26] A. Sears, J. A. Jacko, and M. S. Borella, "Internet delay affects: How users perceive quality, organization, and ease of use of information," in $\mathrm{CHI}$ '97: Late-breaking / Short Talks, S. Pemberton, Ed. New York, NY, USA: ACM, 1997, pp. 353-354.

[27] B. Shneiderman, Designing the User Interface. Upper Saddle River, NJ, USA: Addison-Wesley, 1998.

[28] B. Shneiderman, "Designing trust into online experience," Communications of the ACM (CACM), vol. 43, pp. 57-59, 2000.

[29] R. A. Spreng, S. B. MacKenzie, and R. W. Olshavsky, "A Reexamination of the determinants of consumer satisfaction," Journal of Marketing, vol. 60, pp. 15-32, 1996.

[30] J. Stromer-Galley, "Online interaction and why candidates avoid it," Journal of Communication, vol. 50, pp. 111-132, 2000.

[31] S. S. Sundar, S. Kalyanaraman, and J. Brown, "Explicating web site interactivity," Communication Research, vol. 30, pp. 30-59, 2003.

[32] G. Wu, "Perceived interactivity and attitude toward website," presented at 1999 Annual Conference of American Academy of Advertising, Albuquerque, NM, USA, 1999.

[33] C. Y. Yoo and P. A. Stout, "Factors affecting users' interactivity with the Web Site and the consequences of the users' interactivity," in Proceedings of the 2001 Conference of the American Academy of Advertising, C. R. Taylor, Ed. Villanova, PA, USA: American Academy of Advertising, 2001, pp. 53-61. 